to be explained by the theory of the previous arrest being caused by cardiac paralysis consequent on the circulation of venous blood.

Conclusions relating to Aspiryxia.

That the immediate cause of death from asphyxia is the arrest of the pulmonary circulation appears to be proved by the following facts:-1. When the chest of an animal is opened immediately after death caused by ligature on the trachea, the right cavities of the heart are tound enormously distended, while the left are comparatively empty. 2 . When the heart of an animal is exposed during the progress of asphyxia the right cavities are seen to become distended, while the left cavities, which had been previously gorged, are found to be collapsed and comparatively empty. 3. In the last stage of asphyxia there is a continuous increase of pressure in the pulmonary artery, while the systemic arterial pressure is falling. 4. That the arrest of the circulation through the lungs is due to contraction of the pulmonary arteriolesappears to be proved by theinfluence of agents which are known to paralyse the arterioles-e.g., nitrite of amyl, atropine, and an excessive dose of curare, the effect of which is that deprivation of air is unattended by distension of the right cavities of the heart, and other evidence of obstructed pulmonary circulation, the life of the animal is prolonged for several minutes, and death ultimately results from the toxic action of venous blood upon the cardiac and nervous tissues.

[5. It is an acknowledged fact that these paralysing agents act alike upon the systemic and the pulmonary arterioles, but the successive phenomena of asphyxia are absolutely inconsistent with the idea that the distension of the right side of the heart is a result of systemic arterial obstruction acting backwards through the left cavities of the heart and the lungs.]

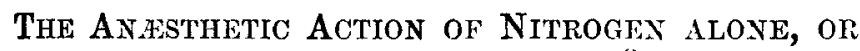
WITH A SMALL PROPORTION OF' OXYGEN.

I have elsewhere stated that the phenomena which result from the inhalation of nitrous oxide as an anesthetic by human beings are strictly analogous with those observed during the early stages of asphyxia. ${ }^{6}$ While some writers maintain that the anæsthetic action of nitrous oxide is due to its preventing access of free oxygen to the system, others believe that it has a "specific aniesthetic action." It occurred to me that some light might be thrown upon this subject by the administration of pure nitrogen. Accordingly I obtained from the Scotch and Irish Oxygen Company of Glasgow a cylinder containing 100 cubic feet of compressed nitrogen, in which the proportion of oxygen present was only 0.5 per cent by volume, with 0.3 per cent. of $\mathrm{CO}_{\mathrm{n}}$. As a preliminary trial, Mr. F. W. Braine was good enough to administer this gas in five instances to members of the staff of King's College, who volunteered to submit to the experiments. The result was in each case the production of complete anxsthesia and of general phenomena preeisely similar to those observed from the inhalation of nitrous oxide. Encouraged by these results, Mr. Braine felt justified in administering the gas to patients at the Dental Hospital for anæsthetic purposes. Nine patients took the gas. In every case the result was the production of complete anæsthesia, with general phenomena precisely similar to those observed during nitrous oxide inhalation. The pulse was first full and throbbing, then feeble. In the advanced stage the respiration was deep and rapid, and there was lividity of the surface; the pupils were dilated, and there was more or less jactitation of the limbs. The only difference, in the opinion of some of those present, being that the anæsthesia was less rapidly produced, and somewhat less durable, than that from nitrous oxide, though in each case the tooth was extracted without pain.

On a subsequent occasion the same gas was administered by Dr. Frederic Hewitt at the Dental Hospital. As before, nine patients took the gas. The maximum period required to produce anæsthesia was 70 seconds, the minimum 50 seconds, and the mean time 58.3 seconds. In one case two teeth were extracted without pain. In one case only was pain experienced, and in that case, the tooth having been broken up and not extracted, the patient said she felt a "smashing up." Having on several occasions witnessed the administration by Dr. Hewitt of nitrous oxide mixed with 10 per cent. by volume of oxygen, with the result of producing anæsthesia without lividity or jactitation, I determined to try a mixture of nitrogen with a small pro- portion of oxygen. I therefore obvained from the company above mentioned a cylinder containing forty cubic feet of nitrogen mixed with 3 per cent. by volume of oxygen, and a second cylinder equally charged with a mixture of nitrogen with 5 per cent. by volume of oxygen. These gases were administered by Dr. Hewitt to patients at the Dental Hospital with the following results :-In the case of the 3 per cent. gas, which was given to five patients, the time required to produce anoesthesia varied from 60 to 75 seconds, the average time being 67.5 seconds. In each case the tooth was extracted without pain, the duration of anesthesia being somewhat longer than with pure nitrogen. In each case there was lividity, dilatation of pupils, and more or less jactitation. On the same day Dr. Hewitt gave nitrogen with 5 per cent. oxygen to four patients. With this mixture the time required for the production of anasthesia ranged from 75 to 95 seconds, the average being 87.5 seconds. In each case there was complete ancosthesia, during which one patient had three molars extracted, and although she said she "felt the two last," the sensation appears to have been that of a pull, and not of acute pain. In all of these four cases there was slight lividity before the face-piece was removed, but in only one case was there slight jactitation of the lim $b \%$ The other three patients were perfectly quiescent. The experiments bere recorded suffice to prove that nitrogen, pure or mixed with a small proportion of oxygen, is as complete and apparently as safe an anæsthetic as nitrous oxide. It is to be hoped that those who are engaged in the administration of anæsthetic gases will investigate this interesting subject further, with a view to ascertain whether atmospheric air, partially deprived of its oxygen, may be advantageously substituted as an an asthetic tor nitrous oxide. For the information of those who may be disposed to enter upon such an investigation, I may state that Brin's Oxygen Company (69, Horseferry. road, Westminster) are prepared to supply nitrogen containing from 4 to 7 per cent. of oxygen at the same rates as they now supply pure oxygen-viz., in quantities of twenty cubic feet or less at $4 d$. per cubic foot, of twenty to sixty cubic feet at $3 d$. per cubic foot, and of over sixty cubic feet at $2 \frac{1}{2} d$. per cubic foot, in their own cylinders. Below 4 per cent. of oxygen, nitrogen could be supplied only by special arrangement, and probably at increased cost. Ás before stated, I obtained the gas employed in my experiments from a Glasgow firm, and its cost was therefore increased by the expense of carriage from Scotland.

Savile-row, W.

\section{BUBBLE REMEDIES IN AURAL SURGERY.}

\section{By SIR WM. B. DALBY, F.R.C.S., M.B. CANTAB,} AURAL SLRGEON TO ST. CEORGE'S HOSPITAL.

IT is probable that all departments of medicine or surgery are more or less liable to the introduction of what may be termed "bubble remedies" (using the word "bubble" in the same sense as it applies to companies), but naturally my cognisance of them is chiefly confined to what I learn from patients with whom I am brought in contact in the practice of my own specialty. If I could repeat a half of their experiences as related to me from time to time during the past few years, the belief in the credulity of mankind would become even greater than it must be even now amongst men who have great knowledge of the world. As might be anticipated from their nature, the life of these bubble remedies is brief, their end is occasionally sudden. and the recollection of them soon fades away; but it is, I am sure, not altogether useless to occasionally subject them to the light. They remain in the air for considerable periods before they attract attention, and then their existence is made known by the voices of those who have invested their hrpes in them. In the ordinary course of events the bistory of any new remedy in medicine or surgery includes a trial at a hospital, a discussion at a society where physicians and sur. geons give the advantage of their experience and knowledge to aid the introducer and to criticise his conclusions. A fair trial is given at other hospitals, and it lives or dies according to the measure of its usefulness. It is very different with the bubble remedy. Its origin is at times singularly unobtrusive, and private patients bove the inestimable, or ques tionable, advantage of an early trial. Its constitution is at 
this period of its life too delicate to be submitted to the full blaze of criticism above alluded to. At another time a small pamphlet is greatly circulated, or a few cases (in which it has been tried, rather, it would appear, for the relief of a symptom than a pathological condition) are reported in a nedical journal. These are more suitable methods of introducing it to the world. What is better still, is that it should have been at some time previously tried by some well-known man of good reputation and subsequently abandoned. It then has an air of respectability, and so resembles an after-birth of a child who has failed to survive.

I will mention only a few examples. It seens almost incredible, but is no less a fact, that during the past year or so a company was floated in the City of London, with a capital of $£ 100,000$, the avowed purpose being to purchase a business which possessed the exclusive right of selling what were termed "artificial ear drams" It is now over fifteen years since the use of Toynbee's artificial membrane (at the time an excellent contrivance in cases of perforation of the tympanic membrane) has been given up by aural snrgeons in favour of improved methods. Now practically any form of artificial membrane that is advocated pre. supposes that all perforations which require protection and pressure can have them usefully applied by one form, the fact being that each perforation requires management to be acquired only by experience, after careful examination, and, when any support of the kind is wanted, it must be regulated by the patient, his sensations being the guide in regard to pressure. Alsu many perforations are quite intolerant of all forms of artificial covering or pressure. However, in regard to these "artificial drums," at first some time was spent in advertising a simple modification of Toynbee's artificial membrane (which, under another name, was to cure every conceivable sort of ear trouble), by means of a pamphlet full of testimonials, the value of which may be judged by the fact that the inventor quoted a long passage from one of my lectures published in 1873 , leaving it to be inferred that it applied to his "ear drum" By and by the bubble was floated. The next episode in its history was an account of a meeting of the company, the vendor occupying the position of chairman. It appeared from the report that the harmony of the proceedings was somewhat marred by the presumption of an inquisitive shareholder; and I bave not seen any account of subsequent meetings. That these ear drums had a considerable sale 1 am sure, since numbers of persons who have consulted me had bought them, I am bound to say generally when they had no perforation at all ; for if by chance they had perforations of such a kind as would receive benefit by Toyn bee's artificial membrane, their hearing might probably have been helped by the use of this imitation. Now, it was in this fact that the fractional good so necessary for the success of this venture is to be found, for who could doubt that, if some deaf people could be made to hear better, it might be the case with all? So much for the ear drums, and now for electricity.

In July, 1889, when speaking on the subject of tinnitus, I said : "Perhaps because tinnitus due to degeneration and some other causes is of a constant character, the kind of electricity which finds favour amongst its advocates is the constant current; but whether this or the interrupted is employed, it is generally the personally conducted and continuous as long as posible." This is no doubt perfectly true, but I still think that for a long though fitful life amongst all bubble remedies, for the ear at least, electricity will maintain the leading position. I will endeavour to show why this is by an illustration. Before doing so, however, lest there should be any misapprehension as to my meaning, I wish to state most emphatically that my remarks apply absolutely and entirely to the unscientific use of electricity, and it is most necessary to state this, since the scientific use of this force has achieved so much in both surgery and medicine during recent years. When the tympanic cavity becomes the seat of acute inflam mation, if the aqueduct of Fallopius is destroyed by caries, the portio dura within it is also destroyed, and facial paralysis is of course in this case permanent. If, however, the inflammatory process is of a more limited character, the facial palsy recovers either completely in a period to be counted by weeks or months, as the inflammatory products around the nerve disappear. Since many of these cases are subjected to electricity, those persons who recover naturally attribute it to the treatment adopted. Perhaps it may be said that this process of reasoning applies so often to many other remedies employed in those forms of disease which have a tendency to recover, that it is unfair to suggest the possibility of the facial palsy getting well in the same time as it there had been no electricity. It is, however, difficult to understand how a current of electricity paszed through muscles can expedite the absorption of inflammatory deposit in the aqueduct of Fallopius any more than in hemiplegia it could expedite the changes in a blood-clot in the brain. The same order of events-viz, treatment by electricity, and, if recovery, this attributable to treatment-takes place in so many nervous and inflammatory troubles connected with the ear that it is employed $f_{0}$ r all sorts of symptoms due to perma. nent change in tissue down to a general tinnitus, which often comes with atheromatous arteries, the results being the same minus the recovery. It is thus that an agent intrinsically of great value in surgery becomes a bubble remedy.

Another reason why electricity as a remedial agent will always be more or less in $r=q u e s t$ may perhaps be found in the fact that the minds of many people are peculiarly liable to its fascinations. The idea is present to them that we live in an age of electricity, and anything short of miracles - in which they also believe up to a pointmay be expected from it. The knowledge, too, that undoubtedly the use of the electric current is of very real service in some departments in surgery tends to contirm a possibly waning faith It can be applied, too, in such Ingenious ways to parts of the body out of sight, and this is an attractive idea. A gain, if the process is attended with acute pain, the treatment is apt to come to an abrupt conclusion, but as a set off to this wbat a delightful revelation it is to find that cocaine can be applied to the aperture which is being acted on--the nose, or some other openingand any objection on the score of pain may be disposed of. To put the matter briefly, is it not within the experience of most practitioners that those who suffer from progressive disease, or unrelieved symptoms, and who naturally fly to something outside the routine of treatment which they have vainly tried, turn their eyes towards electricity as offering a better chance than most of the empty helps held out to them in their dire distress? The same kind of apparent soundness at the base above alluded to-viz., the recovery under treatment, and not due to treatmen - was to be noted in the wholesale injections of deaf people by pilocarpine, which quite recently took place, but the faith in which has been rudely shaken by a paper in THE LANCET of Jan. 3rd from Politzer, who made the original experiments with pilocarpine as far back as 1879 , and who, having subsequently given his experience and views on the subject, now finds it necessary to write in such scathing terms on "the abuse" of this treatment. He there speaks of " practitioners who subject their patients to a long and wearisome course of treatment with pilocarpine," and says, "I feel it my duty to say that they are not too conscientious in the discharge of their calling." It is much to be boped that this protest will be largely and carefully read, for during the spring and summer of 1890 the c ondition of patients who consulted me after being injected in this way were almost lndicrous as to the variety of the ailments for which it had been employed. For the most part these people belonged to the unsuccessful division, and included old gentlemen who objected strenuously to senile degeneration, the middle-aged and the young whose hearing was defective from the many causes which unhappily admit of no alleviation, but they included none of whom it could be said they had not given it a fair trial. One young man out of many I especially remember, who in consequence of central changes was impervious to sound of every sort, both before and after be had been sub. jected to eighty injections, and this was after or before (I forget which, but it is unimportant) a long course of electricity. It may not unreasonably be asked why such wholesale injections did not, even before Professor Politzer's protest, elicit an outspoken disapproval of the practice? In the first place, it is a matter of common knowledge that in the secondary stage of syphilis patients often become deaf and completely recover under the ordinary constitutional measures without any especial treatment for the loss of perception to sound, the conducting power remaining good. Those who were injected of course recovered their hearing, and attributed it to the injections In the later stages of constitutional syphilis, or in the inherited variety especially, the course of events is different. In the second place, it must be remembered that the subject of ear affections does not attract the attention of many, and 
so they did not feel competent to express dissent or assent in the matter. In the third place, this is not the only occasion when injections of fluid have been practised with insufficient data, even with the highest objects in view. Indeed, have not recent events shown that there was for a moment a danger lest a wave of enthusiasm should swamp the intelligence of the College of Physicians, and this danger was only averted by the better judgment of a majority and the sagacity of its guiding spirit? This I conceive to be the explanation of the limited vitality of the pilocarpine craze-a vitality which has been further limited oy Dr. Politzer, who at least, it must be admitted, may fairly claim to set bounds to the employment of an agent which he was the first to apply to ear disease.

The bubble remedy, chameleon-like in its hues, occasionally assumes the aspect of a surgical procedure. In approaching the subject as delicately as possible, let me say I have sometimes hoped it may be possible that there exists in the human mind a faculty-undeveloped unless called into activity-which permits the possessor of it to persuade himself of the inutility and general harmfulness of some portion of the human body (not in the precise instance of his own body, but in that of others). Unless this delusion is within the range of possibility, how are we to explain the determination with which some practitioners exirpate an apparently unoffending portion of the organism for reasons which appear to be not only quite illogical, but which require the profoundest ingenuity even to enunciate? For example, I have been asked to give an opinion somewhat in this way: "I am suffering from [here follow a variety of symptoms which include deafness and tinnitus, but by no means conclude with these troubles]. Do vou think I should be cured ty the removal of my [right or left] middle turbinated bone?" This upon examination being found quite healthy, the opinion in the negative is given without much difficulty, without the expenditure of many words or any comments. The same question has, $I$ know, been asked of many others besides myself. As a surgical procedure, this operation is outside the pale of serious discussion, and I mention it only as an example of a bubble remedy that the very mention of it may possibly hasten its inevitable bursting.

If this operation or mutilation (whichever the reader may elect to term it) is devoid of plausibility, it was not so with another, which is now defunct-viz., division of the tensor tympani muscle, but which, at the period of its birth and early in its brief and chequered career, attracted considerable attention. The conception was not wanting in brilliancy if the results of the proceeding included dulness (in hearing), and it was easy and reasonable at first sight to imagine that the division of this muscle would relieve permanent tension, especially if it had undergone permanent contraction. I have even heard it alluded to at one of the medical societies in London as a recognised operation. It may have been recognised, but certainly by those who were familiar with its results (and especially by those upon whom it was performed) it was recognised as a failure so far as any change for the better in hearing was concerned, and a very decided change for the worse in the cases which came before my notice. I have elsewhere described it as including in its history "a flight of the imagination, a brief notoriety, and a burial in oblivion so rapid as falls to the lot of few achievements in surgery," and I see no reason to alter this description in paying a tribute to the dead.

Such are some of the bubble remedies which float over the area of aural surgery, but which "vanish into thin air" as they emerge into the clear light of day.

Savile-row, $W$.

\section{GOUTY FINGERS.}

By EMIL PFEIFFER, M.D., Wiesbaden.

THE celebrated English physician, William Heberden, in "nis Commentaries, published shortly after his death, about the end of the last century, has a chapter under the heading "De Nodis Digitorum," the tenour of which runs as follows "Nunquam rite intellexi naturam tumorum, qui interdum nascuntur, ad pisi magnitudinem, prope tertium digitorum articulum. Nihil certe illis commune est cum arthridite;

\footnotetext{
I Gulielmi Heberdeni Operæe Medica Commentarii, cap. xxviii., 1802.
}

quoniam in multis reperiuntur, quibus morbus ille est incognitus. Per hominis setatem manent, vacant omni dolore, neque spectant ad ulcerationem. Proinde deformitas major est quam incommodum : quamquam motus digitorum aliquantulum impeditur." From this description these formations have in subsequent publications been named "Heberden's nodes," the name by which they are known at the present day. The accompanying illustration, Fig. 1, taken from a cast in the museum of St. Bartholomew's Hos. pital, London, and copied from Dr. A. E. Garrod's work, ${ }^{2}$ gives a very faithful representation of the affection. Heberden's

\section{FIc. 1.}

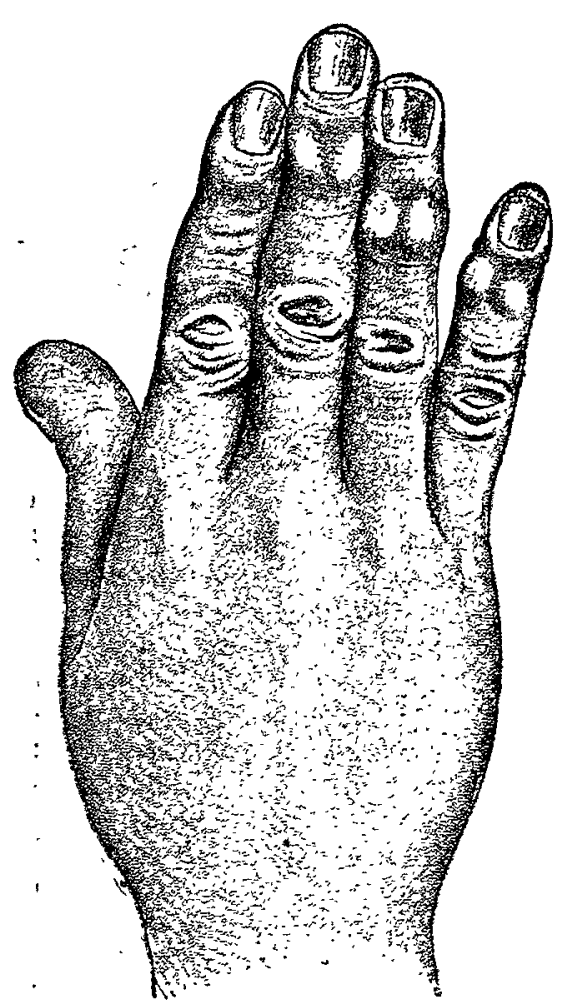

doubts regarding the formation of the nodes described by him were twofold. While he was unable to determine the exact nature of the materials of which they were composed, as well as the parts involved, he could not arrive at a decided opinion as to the cause of the affection.

As to the first point, we have been informed by the anatomical investigations of Charcot that the nodes arise from exostoses round the heads of the second and third phalanges. These exostoses are well shown by the drawings which this author has published (Fig. 2). ${ }^{3}$ It is evident from these

Fig. 2.
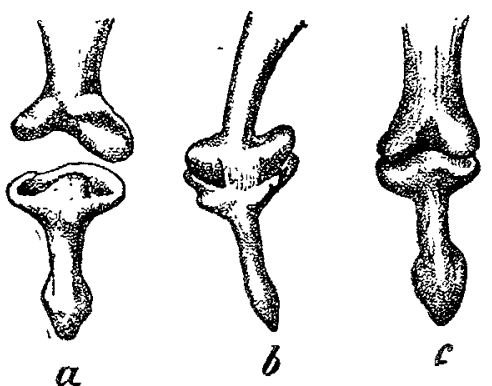

a represents the phalanges from the back, and $b$ the side view. For purposes of comparison he aives a delinea tion of the dorisal surface of $a$ normal phalangeal joint, shown in $c$.

engravings that the nodes are formed by real exostoses and have nothing to do with the tophi of gouty patients.

The second point-the etiology of the disease-has given rise to much greater difference of opinion among writers on this subject. From the little that Heberden wrote we may conclude that he had occupied himself mainly with this question, and that his doubts as to the nature of the nodes were, perhaps, essentially connected with their etiology; but he leaves us in no doubt as to his opinion that they have "no connexion with gout, being found," as he says,

2 A Treatise on Rheumatism and Rheumatoid Arthritis. London: Griffin, 1890. Fig. 15, p 266.

$\because$ (Euvres Completes, tom. vii., planche 1, figs. 4, 5, 6. Paris, 1889 